\begin{tabular}{ll}
\hline POLITEIA/ POLITEIA: Jurnal Ilmu Politik \\
\\
Politeia, 11 (2) (2019): 58-64 \\
ISSN 0216-9290 (Print), ISSN 2549-175X (Online) \\
Available online https:/ / talenta.usu.ac.id/ politeia \\
\hline
\end{tabular}

\title{
Dampak Kebijakan Embargo Negara Arab Terhadap Ekonomi Qatar
}

\author{
Fajar Anugrah Tumanggor* \& Adil Arifin
}

Departemen Ilmu Politik, Fakultas Ilmu Sosial dan Ilmu Politik

Universitas Sumatera Utara

\begin{abstract}
Abstrak
Studi ini adalah studi tentang kebijakan embargo negara Arab terhadap ekonomi Qatar. Fokusnya membahas tentang bagaimana dampak yang ditimbulkan dari kebijakan embargo negara Arab terhadap ekonomi Qatar. Temuan studi ini antara lain ada dampak negatif dan positif yang ditimbulkan dari kebijakan ini. Negatif meliputi: Minyak dunia, penerbangan komersil, pelayaran, pangan, pasar, saham, keuangan, asuransi, dan bank. Sedangkan positif meliputi: transportasi, pangan, perdagangan, keuangan, dan penerbangan komersil. Metode yang digunakan adalah metode deskriptif.
\end{abstract}

Kata Kunci: Negara Arab, Embargo, Ekonomi Qatar

\begin{abstract}
Abstrak
This study is a study of the Arab country's embargo policy on Qatar's economy. The focus is on how the impact of the Arab country's embargo on Qatar's economy. The findings of this study include, among other things, the negative and positive impacts arising from this policy. Negatives include: World oil, commercial flights, shipping, food, markets, stocks, finance, insurance, and banks. While positives include: transportation, food, trade, finance, and commercial aviation. The method used is descriptive method.
\end{abstract}

Keywords: Arab country's, embargo policy, Qatar's economy

How to Cite: Tumanggor, F. A. (2019). Dampak Kebijakan Embargo Negara Arab Terhadap Ekonomi Qatar. Politeia: Jurnal Ilmu Politik, 11 (2): 58-64

*Corresponding author:

E-mail: anugr4hf@gmail.com 


\section{PENDAHULUAN}

Timur Tengah bagi kalangan ilmuwan politik dipandang sebagai sebuah daerah yang masih sulit untuk dideskripsikan. Beragam pandangan hadir untuk menjawab dimana sebenarnya daerah Timur Tengah. Dalam perkembangannya, kalangan ilmuwan politik memiliki tiga pandangan terkait Timur Tengah. Pertama, daerah yang meliputi negara-negara Arab-Non-Afrika ditambah Iran dan Israel. Dalam pengertian ini, negara semisal Alzajair dan Maroko tidak termasuk di dalam nya. Kedua, daerah Timur Tengah meliputi negara-negara Liga Arab ditambah Iran, Israel, dan Turki. Jadi, daerah-daerah yang berbahasa maupun yang berbudaya Arab seperti beberapa terletak di daerah Afrika Utara (Aljazair, Maroko, Libya) dikategorikan masuk ke dalam wilayah Timur Tengah. Ketiga, wilayah yang menjadi lokus kedua pandangan sebelumnya ditambah negara semisal Afganistan, Pakistan, dan beberapa republik Muslim yang ada di Asia Tengah bekas jajahan Uni Soviet.

Timur Tengah memiliki lebih dari setengah total cadangan minyak di seluruh dunia, dan menjadi penentu pasar minyak dunia. Cadangan terbesar ada di Arab Saudi yang memiliki sekitar 36 persen dari total cadangan minyak di Timur Tengah. Disusul Irak 16 persen, UEA 14 persen, Iran 13 persen, Kuwait 13 persen, Libya 4 persen, Oman 1 persen, Qatar 1 persen, Yaman 1 persen, dan Aljazair 1 persen. Akumulasi ini menempatkan Timur Tengah memiliki kekayaan minyak sebanyak 49 persen dari total minyak dunia. Oleh karena kekayaan yang begitu melimpah, posisi Timur Tengah menjadi ladang konflik perebutan minyak dan gas alam dunia. Sehingga tak berlebihan kemudian dapat dikatakan bila persediaan minyak menurun, maka dipastikan ekonomi dunia akan terguncang.

Salah satu negara Timur Tengah ialah Qatar. Qatar adalah sebuah negara emirat di Timur Tengah yang terletak di sebuah semenanjung kecil di Jazirah Arab di Asia Barat. Satusatunya batas darat mereka adalah Arab Saudi di selatan dan sisanya berbatasan dengan Teluk Persia. Teluk ini juga yang memisahkan Qatar dari negara Bahrain. Qatar beribu kota di Doha. Luas dari negara Qatar yakni 11.572 km2. Jumlah penduduk Qatar perhitungan tahun 2015 yakni sebesar 2.120.129 jiwa dengan jumlah kepadatan yakni sebesar $175 / \mathrm{km} 2$. Total pendapatan domestik bruto Qatar sebesar \$320.544 miliar dengan jumlah perkapita sebesar \$129.726 (2016) yang menempatkan Qatar menjadi negara dengan penghasilan perkapita tertinggi nomor tiga di dunia.

Tanggal 5 Juni 2017, Qatar diembargo oleh negara Arab. Negara yang awalnya memutuskan hubungan diplomatik ialah Arab Saudi, Uni Emirat Arab, Bahrain, Mesir, dan Maladewa. Kemudian secara berurut diikuti oleh negara-negara lain se kawasan. Mereka ialah Komoro, Mauritania, Libya, Yaman. Sedangkan, penurunan tingkat hubungan diplomatik dengan Qatar tanpa pemutusan hubungan sepenuhnya ialah Chad, Djibouti, Eritrea, Yordania, Nigeria, dan Senegal. Namun penulis 
memfokuskan negara Arab pada negara Uni Emirat Arab, Arab Saudi, Bahrain, dan Mesir.

Terjadinya pemutusan hubungan diplomatik yang dilakukan negara Arab terhadap Qatar terjadi bukan tanpa faktor. Ada beberapa faktor pemicu nya. Antara lain, pertama, isu terorisme. Qatar diduga oleh negara Arab mendanai organisasi ekstremis dengan tujuan terorisme. Salah satu nya Ikwanul Muslimin. Ikwanul Muslimin sangat tidak disukai oleh negara Arab utamanya oleh Arab Saudi dan UEA. Ia dianggap sebagai organisasi radikal yang sangat membahayakan stabilitas negara Arab.

Kedua, hubungan dengan Iran. Qatar mempertahankan hubungan yang relatif baik dengan Iran. Qatar dan Iran berbagi kepemilikan ladang gas kondesat di Pars Selatan-Dome Utara, yang sejauh ini merupakan ladang gas alam terbesar di dunia. Faktor geostrategi yang menjadi hal signifikan dalam pola hubungan kedua negara tersebut menjadi basis kecemburuan Arab Saudi dan beberapa negara Arab lainnya. Iran masih dianggap sebagai negara yang berbahaya.

Ketiga, Konferensi Tingkat Tinggi (KTT) Riyadh 2017. Isu adanya pemutusan hubungan diplomatik yang dilakukan negara Arab terhadap Qatar semakin berhembus kencang saat KTT Riyadh 2017. Sebagai bagian dari KKT Riyadh, akhir Mei 2017, banyak pemimpin dunia termasuk presiden Amerika Serikat Donald Trump mengunjungi kawasan ini. Trump memberikan dukungan kuat bagi upaya Arab Saudi dalam memerangi negara dan kelompok yang bersekutu dengan Ikhwanul
Muslimin. Dukungan Trump diduga telah menguatkan negara-negara Sunni lainnya mengikuti Arab Saudi untuk mengambil sikap melawan Qatar.

Keempat, peretasan. Situs web Qatar News Agency dan platform media pemerintah lainnya diduga diretas pada Mei 2017. Menurut Al Jazeera (media Qatar), peretas menulis komentar palsu di Qatar News Agency yang dikatikan dengan Emir Qatar, Sheikh Tamim bin Hamad Al-Thani, yang menyatakan dukungannya untuk Iran, Hamas, Hizbullah, dan Israel. Dalam komentar tersebut kesimpulannya agar Iran tidak dipandang sebelah mata oleh negara Teluk, karena ia adalah salah satu kekuatan besar yang ada di Timur Tengah. Qatar menuding UEA, Arab Saudi, dan Amerika berada di belakang ini semua. Kondisi ini kembali membuat hubungan kedua belah pihak semakin memanas.

Studi ini membahas apa dampak yang ditimbulkan dari kebijakan embargo negara Arab terhadap ekonomi Qatar.

\section{METODE PENELITIAN}

Penelitian ini adalah bersifat deskriptif. Pengumpulan data dengan teknik studi pustaka (library research). Analisis data menggunakan analisis kualitatif.

\section{PEMBAHASAN}

\section{Dampak Kebijakan Embargo}

Dalam kebijakan embargo yang dilakukan oleh negara Arab terhadap Qatar, ada dua dampak yang ditimbulkan, yakni: negatif dan positif.

Dalam dampak negatif, ada beberapa variabel yang menjadi fokus peneliti. 
Antara lain adalah: pertama, minyak. Dalam hal minyak, Qatar mengalami penurunan sebesar 8 persen dari Juni-Juli 2017 dengan keempat negara Arab. Kedua, dalam penerbangan komersil, Qatar mengalami penuruan penerbangan hingga sekitar $1 / 2$ persen dari total penerbangan awal yakni sekitar 80 penerbangan setiap hari. Ketiga, dalam bidang pelayaran, dampak yang ditimbulkan dari embargo ini ialah penutupan jalur pelayaran atau dermaga Uni Emirat Arab yakni Fujairah dan Jebel Ali yang menjadi tempat transit dan distribusi dagang Qatar.

Keempat, dalam bidang pangan, Qatar mengalami lonjakan pembelian pangan sekitar 4,5 persen dari bulan JuniJuli 2017. Selain itu, kondisi tersebut memicu terjadinya antrian panjang di swalayan dan pusat perbelanjaan Qatar. Kelima, dalam bidang pasar dan saham, Qatar mengalami penurunan nilai saham sekitar \$15 miliar. Yang juga turut memengaruhi turunnya perdagangan Qatar hingga 40 persen.

Keenam, dalam bidang keuangan, asuransi dan bank, Qatar mengalami penurunan dalam bidang mata uang. Mata uang Qatar turun pada posisi AA- (yang menandakan nilai mata uang lemah) dari sebelumnya AA (yang menandakan nilai mata uang tinggi). Dalam bidang asuransi, terjadi pemutusan kerjasama perusahaan asuransi antara UEA dan Qatar. Dan terakhir, dalam bidang perbankan, Qatar melakukan PHK untuk mengurangi insentif yang berlebih.

Selain dampak negatif yang ditimbulkan, ada dampak positif yang juga ditimbulkan dari kebijakan embargo negara Arab terhadap Qatar, antara lain yakni: pertama, transportasi. Dalam bidang transportasi, Qatar mengalami peningkatan jumlah transportasi yang naik hingga 1.000 armada pasca pemutusan diplomatik. Dan dalam dua bulan pasca pemutusan, insentif yang diterima oleh pengelola taxi melonjak. Kedua, pangan. Dalam hal pangan, Qatar menjalin hubungan yang baik dengan Iran pasca pemutusan hubungan diplomatik. Hal itu ditandai dengan pengiriman sekitar 100 ton buah dan sayur-sayauran setiap hari.

Ketiga, perdagangan. Dalam hal perdagangan, Qatar mengalami peningkatan perdagangan dengan ketiga negara, yakni: Iran, Turki dan Pakistan. Dalam waktu kurang enam bulan, perdagangan angara Iran dan Qatar meningkat 117 persen. Satu diantaranya ialah perdagangan non-minyak yang meningkat sekitar 30,8 persen dengan nilai perdagangan sekitar $\$ 67,5$ miliar dalam lima bulan pasca pemutusan. Bahkan dalam bidang gas, Qatar meningkatkan nilai ekspornya hingga 30 persen dengan Iran. Sementara Turki, mencapai \$20 miliar, yang tertinggi kedua dari negara manapun. Dan untuk Pakistan, pada awal Desember 2017 lalu, dibuka rute perdagangan langsung antara pelabuhan Pakistan dan Qatar.

Keempat, keuangan. Dalam bidang keuangan, ekonomi negara Qatar menurut IMF tumbuh 3,1 pada tahun 2018, naik 2,5 persen dari tahun 2017. Hal ini terjadi karena Qatar memompa hampir \$40 miliar ke ekonomi Qatar. Sehingga, di bulan Juli pasokan uang tumbuh lebih dari 8,3 persen dari bulan sebelumnya. Sementara basis moneter tumbuh 1,7 persen. Hal ini menandai kebangkitan ekonomi keuangan Qatar. Kelima, penerbangan komersil. Dalam bidang penerbangan komersil, Qatar membuka 10 rute baru di akhir tahun 2017. Dan akan melakukan 10-15 lagi di tahun 2018.

Dampak negatif dan positif yang ditimbulkan oleh kebijakan embarg negara Arab terhadap Qatar dapat kita pandang dari perspektif kebijakan luar negeri 
dengan pendekatan realis. Realisme merupakan pendekatan yang digunakan dalam studi polugri yang asumsinya berdasarkan pada pandangan anarki, self help, dan pemahaman aktor rasional dari negara. Ditambah, realisme didasarkan pada suatu keadaan yang terjadi (realitas), bukan seharusnya seperti yang diyakini kaum idealis. Dengan demikian, realis mengklaim bahwa agar bisa bertahan, negara harus bertindak sebagai pemaksimalan kekuatan. Menurut Holsti, kebijakan luar negeri suatu negara sangat dipengaruhi oleh kondisi posisinya di dalam sistem internasional dan distribusi kekuasaan di dalamnya.

Menarik untuk mengkaji kalimat "negara harus bertindak sebagai pemaksimalan kekuatan". Dalam konteks anarki, embargo yang dilakukan oleh negara Arab terhadap Qatar adalah bukti pemaksimalan kekuatan yang dilakukan oleh negara Arab dalam konteks internasional. Kekuatan itu dibuktikan dari pemutusan hubungan jalur transportasi, media, dan ekonomi yang secara tidak langsung mempengaruhi internal negara Qatar.

Pemberlakuan embargo tersebut tidak saja mempengaruhi ekonomi Qatar, tapi juga membuat renggang kembali hubungan Qatar dengan beberapa negara Arab. Keadaan ini terus menambah deretan panjang bagaimana kecemburuan terhadap suatu negara kembali menemukan definisi terbaiknya. Kecemburuan itu ditandai dengan pembentukan aliansi dengan berporos pada Arab Saudi sebagai koordinator dari pemutusan hubungan diplomatik terhadap Qatar.

Kecuriagaan tersebut bukan tanpa alasan. Keadaan itu berasal dari kenyataan bahwa untuk survive dan mencapai level subsisten manusia perlu hidup bersatu berdasarkan suatu solidaritas kelompok.
Kohesi dalam grup ini juga berpotensi untuk berkonflik dengan kelompokkelompok lain. State merupakan pengelompokan manusia (groupism) yang paling penting dewasa ini, dan sumber kohesi in-group yang paling kuat adalah nasionalisme. Sementara itu, aktor-aktor yang lain dinilai kurang penting.

Menurut pengamat Timur Tengah dari Lembaga Ilmu Pengetahuan Indonesia (LIPI), M. Hamdan Basyara, mengatakan bahwa Qatar dapat peringatan dari negara-negara Teluk karena dinilai terlalu maju berinovasi di sektor ekonomi dan politik. Hal ini dapat kita buktikan dari tingkat pendapatan Qatar yang sangat tinggi untuk sekelas negara kecil di kawasan Teluk. Menurut data Dana Moneter Internasional (IMF) tahun 2016, PDB per kapita Qatar menempati posisi nomor 3 tertinggi di dunia. Pendapatan per kapita negara ini mencapai US\$129.726 (2016). Sementara Arab Saudi , UEA , Bahrain, dan Mesir secara berurut tingkat pendapatannya hanya \$24.454, \$44.740, \$24.199, dan \$3.724. Alhasil, pertarungan kekuatan dalam persaingan untuk menjadi yang terhebat tak dapat dihindarkan.

Dalam kaitan dengan polugri, dengan melihat asumsi di atas harus dipahami bahwa negara sebagai aktor utama harus menghadapi negara lain seperti bola biliar yang sedang dimainkan di atas mejanya bergerak dan bertubrukan satu sama lain. Yang membuat konsep bola biliar ini menarik adalah adanya perasaan ketidakamanan bersama antarnegara dan ketiadaan otoritas kekuatan politik yang disebut anarki di dunia internasional. Tindakan negaranegara karena itu didorong oleh keinginan untuk survive atau mempertahankan diri dari ancaman yang terus-menerus. Karena tiap negara mengejar keamanan dengan 
meningkatkan kekuatan militernya, maka politik luar negeri pun diorientasikan pertama kali untuk mempertahankan keamanan (power). Mereka menghadapi dilema keamanan atau security dilemma yang tiada habisnya.

Dalam pengertian di atas, bila kita lihat dari kasus negara Arab dan Qatar, Qatar berjuang keras untuk bangkit dari keterpurukan ekonomi akibat embargo yang dilakukan oleh 4 negara Arab yakni Mesir, Bahrain, Arab Saudi, dan Uni Emirat Arab. Asumsi realis dengan mengatakan bahwa dunia seperti bola biliar dalam gelanggang nya yang saling bertubrukan memang betul adanya. Bola biliar tersebut harus kuat untuk bertahan dari tubrukan-tubrukan yang terjadi. Dan Qatar, dengan beragam pendekatan yang telah penulis sebutkan di bagian sebelumnya berusaha merestrukturisasi ekonomi dan keamanan yang tampak kacau di awal-awal embargo hingga saat ini.

Dalam sektor pangan misalnya, Qatar terus berusaha menggenjot agropreneurs untuk mencegah imbas ekonomi secara berkelanjutan. Sektor pangan memang yang paling rentan terkena imbas karena mayoritas pangan Qatar berasal dari impor. Penguatan ini pastinya akan mencegah pendiktean Qatar oleh negara-negara yang tidak menyukainya. Selain itu, adanya kebijakan yang berhaluan penguatan internal Qatar diperlukan, mengingat Qatar akan terus menghadapi dunia yang seperti bola biliar.

Dalam perkembangannya, orientasi polugri yang dilakukan oleh negara Arab terhadap Qatar merupakan cara negara Arab dalam mendikte Qatar. Holsti menyebutnya sebagai pembuatan koalisi dan pembangunan aliansi. Berbeda dengan isolasi, orientasi polugri ini berangkat dari ketidakmampuan negara, baik dalam pertahanan maupun ekonomi, untuk berdiri sendiri. Jadi karena itu, mereka berusaha melakukan koalisi diplomatik dan kadangkala melakukan aliansi militer untuk melindungi pertahanan negara.

Aliansi Arab (Mesir, Bahrain, Arab Saudi, dan Uni Emirat Arab) dengan pemimpin utamanya Arab Saudi dalam mengembargo Qatar adalah cerminan penghimpunan kekuatan yang dilakukan oleh negaranegara untuk mencapai tujuan yang diinginkan. Negara Arab menyadari, hanya dengan menghimpun kekuatan mereka bisa melakukan dominasi di kawasan Arab. Bahkan negara-negara yang lemah secara ekonomi seperti Yaman yang ikut serta memutuskan hubungan diplomatik masuk dalam komplotan yang di dalam aliansi tersebut mereka juga pernah saling berkonflik.

Tiada yang abadi selain kepentingan seolah menemukan definisi terbaiknya dalam aliansi tersebut. Yaman dan Arab Saudi misalnya pernah terlibat dalam konflik yang sempat membuat kedua negara renggang. Hal itu terjadi karena pimpinan Saudi mengintervensi konflik Yaman sejak Maret 2015 untuk mengusir pemberontak Houthi dan mendukung presiden Abd-Rabbu Mansour Hadi yang diakui internasional, dan dipaksa mengasingkan diri oleh 
Houti. Kabarnya, lebih dari 100 ribu warga Yaman, sebagian besar anakanak tewas akibat perang tersebut. Akan tetapi, dalam kasus Qatar mereka memilih bergabung untuk memboikot Qatar. Dalam hal ini dapat kita lihat bagaimana kepentingan menjadikan mereka aliansi.

\section{SIMPULAN}

Kebijakan embargo yang dilakukan oleh negara Arab memiliki dampak yang signifikan bagi Qatar, baik dari sisi negatif dan positif. Dalam sisi negatif, Terdapat beberapa variabel, yakni: Minyak dunia, penerbangan komersil, pelayaran, pangan, pasar, saham, keuangan, asuransi, dan bank. Sementara dalam sisi positif, terdapat beberapa variabel antara lain: transportasi, pangan, perdagangan, keuangan, dan penerbangan komersil.

\section{DAFTAR PUSTAKA}

Collins, G. (2018). Anti-Qatar Embargo Toward Strategic Failure. Texas (US): Rice University Press.

David Kirpatrick dalam 5 Arab States Break Ties With Qatar, Complicating U.S Coalition-Building", diakses dari https://mobile.nytimes.com/2017/06/05/ world/middleeast/qatar/-saudi-arabiaegypt-bahrain-united-arab-emirates.html pada tanggal 19 November 2017 pukul 22.03 .

Eby H. A. (2011). Pengantar Analisis Politik Luar Negeri: Dari Realisme Sampai Konstruktivisme. Bandung: Penerbit Nuansa.

Euan McKirdy dalam Middle East Split: The Allies Isolating Qatar, diakses dari edition.cnn.com/2017/06/05/midd leeast/qatar-saudi-arabia-bahrainegypt-uea-relations-index.html pada tanggal 30 Desember pukul 20.35 .
Financial Times dalam What is behind the extraordinary Gulf dispute with Qatar, diakses dari https:/ / www.ft.com.content/3c6b7 224-49d0-11e7-a3f4-c742b9791d43 pada tanggal 7 Januari pukul 21.25.

Ishiyama, Jhon. 2013. Ilmu Politik: Dalam Paradigma Abad Ke-21 (jilid I). Jakarta: Prenada Media Group, hal 555-556.

Lalu Rahadian dalam Pengamat: Krisis Qatar karena Kecemburuan Negara Arab, diakses dari: https://m.cnnindonesia.com/inter nasional/20170610133702-106220788/ pengamat-krisis-qatarkarena-kecemburuan-negara-arab pada tanggal 9 Maret 2018.

Linch, Mary. 2017. Three Big Lesson form Qatar Crisis. Amerika Serikat: George Washington University Press.

Marc Champion dalam Saudi Dispute with Qatar Has 22-Year History Rooted in Gas, diakses dari https://www.bloomberg.com/new s/articles/2017-06-06/saudi-arabias-feud-with-qatar-has-22-yearshistory-rooted-in-gas pada tanggal 30 Desember 2017 pukul 20.01.

Sihbudi, Riza. 1993. Konflik dan Diplomasi di Timur Tengah. Bandung: PT. Eresco.

Titah Ruslin, Ismah. 2013. Memetakan Konflik Timur Tengah (Tinjauan Geografi Politik). Makassar: UIN Alauddin Makassar, Jurnal Politik Profetik, Volume I No.1 Tahun 2013.

Ulrichsen, Kristian Cotes. 2017. The Qatar Crisis. Newyork: George Washington University Press.

Wikipedia, Qatar dalam https://id.m.wikipedia.org/wiki/ Qatar diakses pada tanggal 19 November 2017 pukul 22.14 
Politeia: Jurnal Ilmu Politik, 11 (2) (2019): 58-64 